\title{
Synthesis and Characterization of Polyphosphazenes Modified with Hydroxyethyl Methacrylate and Lactic Acid
}

\author{
Evelyn Carolina Martínez Ceballos, ${ }^{1,2}$ Ricardo Vera Graziano, \\ Gonzalo Martínez Barrera, ${ }^{3}$ and Oscar Olea Mejía ${ }^{4}$ \\ ${ }^{1}$ Facultad de Química, Universidad Autónoma del Estado de México, Paseo Colón esq. Paseo Tollocan, 50120 Toluca, ME, Mexico \\ ${ }^{2}$ Departamento de Polímeros, Instituto de Investigaciones en Materiales, Universidad Nacional Autónoma de México, \\ 04510 Coyoacán, DF, Mexico \\ ${ }^{3}$ Laboratorio de Investigación y Desarrollo de Materiales Avanzados (LIDMA), Facultad de Química, \\ Universidad Autónoma del Estado de México, Km 12 de la carretera Toluca-Atlacomulco, 50200 San Cayetano, ME, Mexico \\ ${ }^{4}$ Centro Conjunto de Investigación en Química Sustentable UAEM-UNAM, Facultad de Química, Universidad Autónoma \\ del Estado de México, Carretera Toluca-Atlacomulco, Km 14.5, Unidad El Rosedal, 50200 San Cayetano, ME, Mexico
}

Correspondence should be addressed to Evelyn Carolina Martínez Ceballos; evycam74@gmail.com

Received 14 March 2013; Revised 29 May 2013; Accepted 25 June 2013

Academic Editor: Carmina Menchaca-Campos

Copyright (c) 2013 Evelyn Carolina Martínez Ceballos et al. This is an open access article distributed under the Creative Commons Attribution License, which permits unrestricted use, distribution, and reproduction in any medium, provided the original work is properly cited.

Poly(dichlorophosphazene) was prepared by melt ring-opening polymerization of the hexachlorocyclotriphosphazene. Poly[bis(2hydroxyethyl-methacrylate)-phosphazene] and poly[(2-hydroxyethyl-methacrylate)-graft-poly(lactic-acid)-phosphazene] were obtained by nucleophilic condensation reactions at different concentrations of the substituents. The properties of the synthesized copolymers were assessed by FTIR, ${ }^{1} \mathrm{H}-\mathrm{NMR}$ and ${ }^{31} \mathrm{P}-\mathrm{NMR}$, thermal analysis (DSC-TGA), and electron microscopy (SEM). The copolymers have a block structure and show two $T_{g}$ 's below room temperature. They are stable up to a temperature of $100^{\circ} \mathrm{C}$. The type of the substituents attached to the PZ backbone determines the morphology of the polymers.

\section{Introduction}

Polyesters, polyorthoesters, polyanhydrides, poly(R-amino acids), and polyphosphazenes are degradable polymers that have been investigated for a variety of biomedical applications such as sutures, drug delivery systems, and scaffolds for tissue engineering [1]. Useful properties can be obtained by blending two different polymers. However, compatible polymer blends require strong molecular interactions between polymer chains [2]. Poly(organophosphazenes) offer an appealing platform for the design and synthesis of novel biodegradable polymers as well as critical advantages for the design of biologically functional macromolecules with a broad structural diversity [3], high functional density, and tailored biodegradability [4]. These polymers are of scientific and technological concern since the first work of synthesis reported by Allcock et al. [5, 6]. Polyphosphazenes (PZs) posses special characteristics, including flame-retardant properties, high resistance to oil and solvents, and feasibility for tailored properties according to the choice of organic, inorganic, or organometallic side groups [7]. As biomaterials they have inherent advantages, due to their biocompatibility and fast degradation rate. In addition, degradation residues, phosphate, ammonia, and side groups are either nontoxic when they are present in small quantities or are easily metabolized by the human body $[8,9]$. Polyphosphazenes are hybrid polymers with a flexible inorganic backbone of alternating phosphorus and nitrogen atoms and organic side groups. Their composition vary from 3 to $10,000(-\mathrm{N}=\mathrm{P}-)$ repetitive units having two substituents $(-\mathrm{R})$ attached to the phosphorus atom [7]. Polyphosphazenes are synthesized by reactions with alkoxides, aryloxides, or amines from a highly reactive macromolecular intermediate, poly(dichlorophosphazene), which is prepared by thermal ring opening polymerization 
<smiles>ClP1(Cl)=NP(Cl)(Cl)=NP(Cl)(Cl)=N1</smiles>

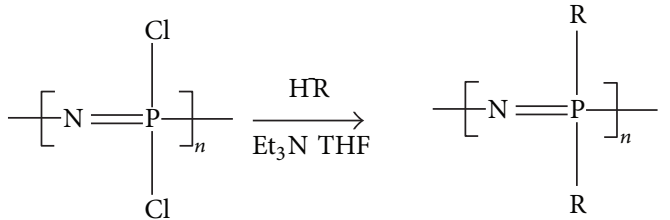<smiles>[R]OCCOC(=O)C(=C)C</smiles>

FIGURE 1: Synthesis by substitution of poly(organophosphazenes).

of hexachlorocyclotriphosphazene (HCCP) at $250^{\circ} \mathrm{C}$. The chlorine atoms can be further replaced via nucleophilic substitution, using amino acid ester, imidazolyl, glyceryl, or glycosyl side groups that are also hydrolytically sensitive [5]. The flexible inorganic backbone of the poly(phosphazene) structure plays an important role in tissue regeneration. It can be modified with ester, anhydride, and unsaturated groups to improve chemical stability and mechanical properties. Cosubstituted poly(organophosphazenes) with unsaturated side groups are used to prepare interpenetrating polymer networks with acrylonitrile, styrene, acrylic acid, and methyl methacrylate, using sequential interpenetrating methods. Such polyphosphazenes can be readily crosslinked either by exposure to heat or to ultraviolet light [10]. In this work, poly[(2-hydroxyethyl methacrylate)-graft-poly(lactic acid)phosphazene] and poly[bis(2-hydroxyethyl-methacrylate)phosphazene] were synthesized by condensation polymerization reactions. The 2-hydroxyethyl methacrylate (HEMA) was selected to improve biocompatibility and bifunctionality. HEMA was firstly attached to the side chain along with glycine-ethyl ester to form a precursor with the unsaturated substituents. HEMA is used for prosthesis, teeth, and bones reconstructive materials, and it is frequently mixed with acrylic polymers, like bisphenol-A-glycidyl-dimethacrylate (Bis-GMA), in photopolymerizable dental resins. HEMA is intended to infiltrate the demineralised dentin and prevent collagen collapse [11]. HEMA melts at about $-12^{\circ} \mathrm{C}$. The lactic acid, LA, was selected because it is a biocompatible and biodegradable material with good mechanical properties and is neither nontoxic nor cancerogenous to the human body $[5,12]$. The poly(lactic acid) (PLA) chemistry involves the processing and polymerization of lactic acid monomer. Lactic acid $\left(\mathrm{HOCH}_{3} \mathrm{CHCOOH}\right)$ is a simple chiral molecule which exists as two enantiomers, L- and D-lactic acid. The polymer is relatively hard, with a glass transition temperature between $60^{\circ} \mathrm{C}$ and $70^{\circ} \mathrm{C}$ and a melting point between 170 and $180^{\circ} \mathrm{C}$.

\section{Experimental}

2.1. Materials and Methods. Hexane (MERK), n-heptane (Aldrich), tetrahydrofuran (THF-Aldrich), and triethylamine (TEA-Aldrich) were distilled from $\mathrm{CaH}_{2}$ and drying with $\mathrm{MgSO}_{4}$. HEMA (Aldrich) and acid lactic (Purac H588) were distilled just before use. HCCP (Aldrich) was purified by two times sublimation $\left(30^{\circ} \mathrm{C} / 0.1 \mathrm{mmHg}\right)$. The melting point of the purified HCCP was $113-114^{\circ} \mathrm{C}$.

ATR infrared spectra were obtained in a Thermo Nicolet Avatar 360 FTIR Spectrometer (Thermo Scientific, USA). The ${ }^{1} \mathrm{H}(400 \mathrm{MHz})$ and ${ }^{31} \mathrm{P}(161.9 \mathrm{MHz})$ Nuclear Magnetic Resonance (NMR) spectra were recorded in the Fourier transform mode with $\mathrm{CDCl}_{3}$ as solvent (Bruker Avance NMR 400, USA). Chemical shifts were relative to tetramethylsilane at $\delta=0 \mathrm{ppm}$ for protons and carbons. The phosphorus chemical shifts were relative to external $85 \% \mathrm{H}_{3} \mathrm{PO}_{4}$ at $\delta=$ $0 \mathrm{ppm}$. The glass transition temperatures $\left(T_{g}\right)$ were measured by differential scanning calorimetry (DSC) at a heating rate of $10^{\circ} \mathrm{C} / \mathrm{min}$ from -100 to $150^{\circ} \mathrm{C}$ under dry nitrogen atmosphere (MDSC 2910 TA Instruments, USA). The thermogravimetric analysis (TGA) were measured in the range of $25-600^{\circ} \mathrm{C}$ at

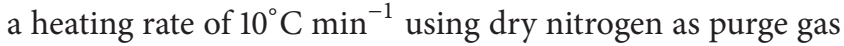
(SDT Q600 TA Instruments, USA). Finally, the morphology of the copolymers were characterized by Scanning Electron Microscopy at an acceleration voltage of $20 \mathrm{kV}$ (JSM5900-LV SEM, JEOL, USA).

2.2. Syntheses of Polymers. The scheme of the poly(organophosphazenes) synthesis by nucleophilic substitution is shown in Figure 1. The single substituted and cosubstituted PZs were obtained from poly(dichlorophosphazene) as described below. The poly(dichlorophosphazene) (PZ) was obtained by melt ring-opening polymerization of hexachlorocyclotriphosphazene (HCCP) under vacuum at $250^{\circ} \mathrm{C}$ for $3 \mathrm{~h}$. After this time, the polymer was dissolved at room 
temperature in anhydrous THF, and it was separated by precipitation into n-heptane. Its characteristics were $98 \%$ yield; characteristic IR bands were 1215 and $748 \mathrm{~cm}^{-1}$ (linear phosphazene); ${ }^{31} \mathrm{P}-\mathrm{NMR}$ peak at $-16.1(\delta=$ ppm relative to $85 \%$ of $\mathrm{H}_{3} \mathrm{PO}_{4}$ at $0 \mathrm{ppm}$ ).

The substitution of poly(dichlorophosphazene) (PZ) with HEMA was made at two molar relations: $1: 3$ and $1: 6 \mathrm{mmol}$ PZ-HEMA. Triethylamine (TEA) was added at $1: 1 \mathrm{mmol}$ relation HEMA : TEA as effective acceptor to trap hydrogen chloride. The PZ was dissolved in THF $(10 \mathrm{~mL})$ under stirring, after 10 min HEMA and TEA were added and the glass vial reactor was kept for two days at room temperature. The product was purified following the procedure described for PZ; the yield was 51\%. The phosphazene backbone characteristic IR bands $\left(\mathrm{cm}^{-1}\right)$ were $2947\left(\mathrm{CH}_{2}\right), 1720(\mathrm{C}=\mathrm{O}), 1635$ $(\mathrm{C}=\mathrm{C}), 1473$ (CO-O), 1033 (P-O-C), 1168 (phosphazene backbone $\mathrm{C}-\mathrm{O})$, and the ${ }^{31} \mathrm{P}-\mathrm{NMR}$ peaks: 1.5 ( $\left.\delta=\mathrm{ppm}\right) ;{ }^{1} \mathrm{H}-$ $\mathrm{NMR}_{\text {HEMA }}[13]$ at $6.0(1 \mathrm{H}), 5.4(1 \mathrm{H}), 4.3(2 \mathrm{H}), 2.0(3 \mathrm{H})$, and $1.7(2 \mathrm{H})(\delta=$ ppm).

The substitution reactions of $\mathrm{PZ}$ with HEMA and LA were carried out in a similar way. The PZ: HEMA : LA molar relation was $1: 3: 3 \mathrm{mmol}$, and for HEMA-TEA the relation was $1: 1 \mathrm{mmol}$. The product was purified following the procedure described for PZ; obtaining a 50\% yield [14]. The typical IR bands $\left(\mathrm{cm}^{-1}\right)$ were 3452 (polymeric-OH), $2947\left(\mathrm{CH}_{2}\right), 1745$ and $1724(\mathrm{C}=\mathrm{O}), 1635(\mathrm{C}=\mathrm{C}), 1477$ and $1150(\mathrm{CO}-\mathrm{O}), 1037(\mathrm{P}-$ $\mathrm{O}-\mathrm{C}$ ), and 1172 (phosphazene backbone) and the ${ }^{31} \mathrm{P}-\mathrm{NMR}$ peaks 1.5 and $0.6(\delta=\mathrm{ppm}) ;{ }^{1} \mathrm{H}-\mathrm{NMR}_{\mathrm{HEMA}}, 6.0(1 \mathrm{H}), 5.4$ $(1 \mathrm{H}), 4.3(3 \mathrm{H}), 2.0(2 \mathrm{H})$, and $1.7(2 \mathrm{H})(\delta=\mathrm{ppm})$, as well as ${ }^{1} \mathrm{H}-\mathrm{NMR}_{\mathrm{LA}}$ peaks: $1.3(3 \mathrm{H}), 3.5(1 \mathrm{H})$, and $11.5(1 \mathrm{H})(\delta=\mathrm{ppm})$.

\section{Results and Discussion}

In the Figure 2(a) we show the IR spectra of PZ-HEMA-1: 3; PZ-HEMA-1: 6, PZ-HEMA-PLA and the Figure 2(b) present de comparative groups (zoom) between the blank and substituent copolymers. The band at $1170 \mathrm{~cm}^{-1}$ corresponds to the phosphazene backbone. The substitution of the chlorine on PZ chain (Figure 2(b)) by the two components is observed by the elimination or reduction of peak in $748 \mathrm{~cm}^{-1}$, also by the presence of a band at $1035 \mathrm{~cm}^{-1}$ corresponding to the interaction $\mathrm{P}-\mathrm{O}-\mathrm{C}$.

With the formation of a new band at $1720 \mathrm{~cm}^{-1}$ for PZHEMA and the evidence of two shifts of similar intensities at 1724 and $1745 \mathrm{~cm}^{-1}$ for PZ-HEMA-LA, the carbonyl groups of the monomers could be confirmed within the copolymer due the substitution of the chlorines.

Additionally, the new bond $\mathrm{P}-\mathrm{O}-\mathrm{C}$ could be confirmed too with the absence of the band of the $\mathrm{OH}$ at $3516 \mathrm{~cm}^{-1}$ and the presence of the double bonds bands in $1635 \mathrm{~cm}^{-1}$ for the HEMA (Figure 2(a)). In the case of lactic acid, the $\mathrm{OH}$ band decreases for primary alcohol, but remain present for the polymeric $\mathrm{OH}$ in $3452 \mathrm{~cm}^{-1}$, an indication that we conservated the $\mathrm{OH}$ of lactic acid in the copolymer.

The stepwise substitution reactions of $\mathrm{PZ}$ were monitored by ${ }^{31} \mathrm{P}-\mathrm{NMR}$ spectroscopy (Figure 3 ). The PZ spectrum shows a peak at $-16.1 \mathrm{ppm}$ corresponding to low molecular

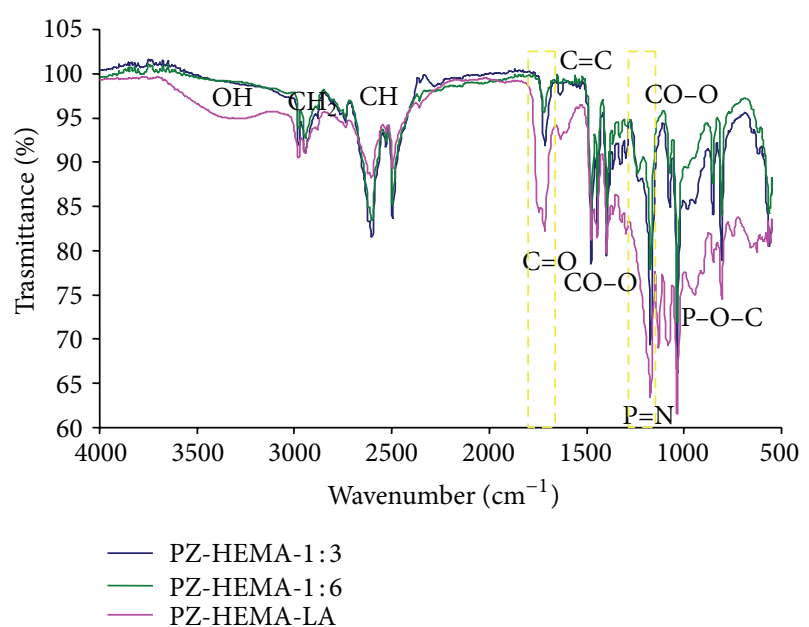

(a)

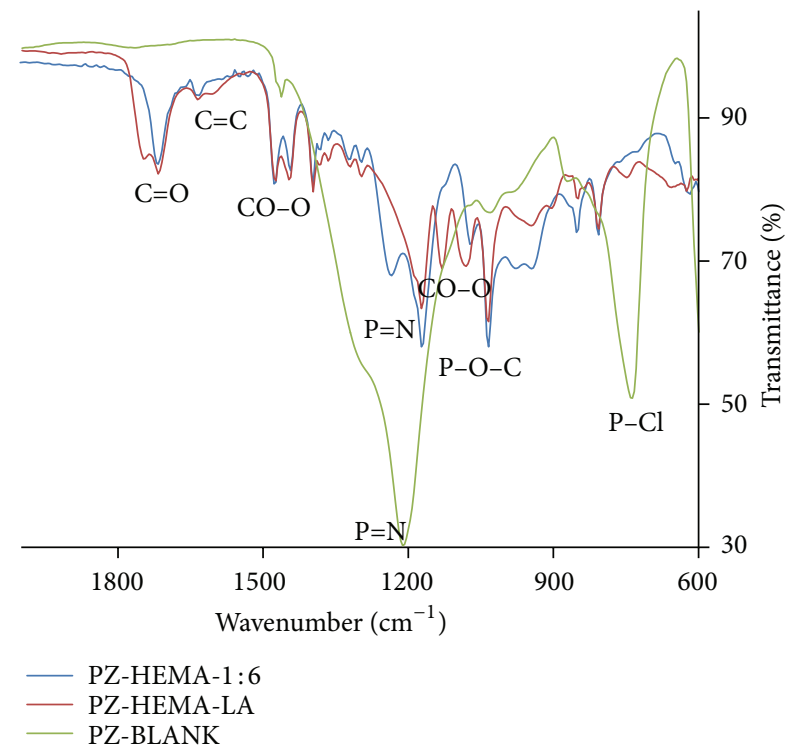

(b)

FIGURE 2: FTIR spectra of (a) PZ-HEMA-1:3, PZ-HEMA-1:6, and PZ-HEMA-LA and (b) PZ-BLANK, PZ-HEMA-1:6, and PZHEMA-LA.

weight $\left[\mathrm{P}\left(\mathrm{Cl}_{2}\right)=\mathrm{N}\right]_{\mathrm{n}}[15]$, while the polymers PZ-HEMA$1: 3$, PZ-HEMA-1:6, and PZ-HEMA-PLA show a peak in positive values; it may be presumed that chlorine atoms were completely replaced by subsequent reaction. The peak at $1.5 \mathrm{ppm}$ is assigned to modified phosphazene $\left[\mathrm{P}(\mathrm{OR})_{2}=\mathrm{N}\right]_{\mathrm{n}}$. In addition, the PZ-HEMA-1:3 shows a peak at $20 \mathrm{ppm}$ which is assigned to [R-P=O]. When the HEMA ratio was increased to $6 \mathrm{mmol}$ a complete chlorine substitution was obtained, the spectrum only presents one peak; in another hand, for PZ-HEMA-LA, another peak appears at $0.6 \mathrm{ppm}$ assigned to the substitution of chlorine by LA.

The ${ }^{1} \mathrm{H}$ NMR spectrum of PZ-HEMA-1:6 and PZHEMA-LA is shown in Figure 4. We observed the peaks corresponding to different hydrogens of the organic substituents. The presence of the signals at 6 and $5.58 \mathrm{ppm}$ indicates that 


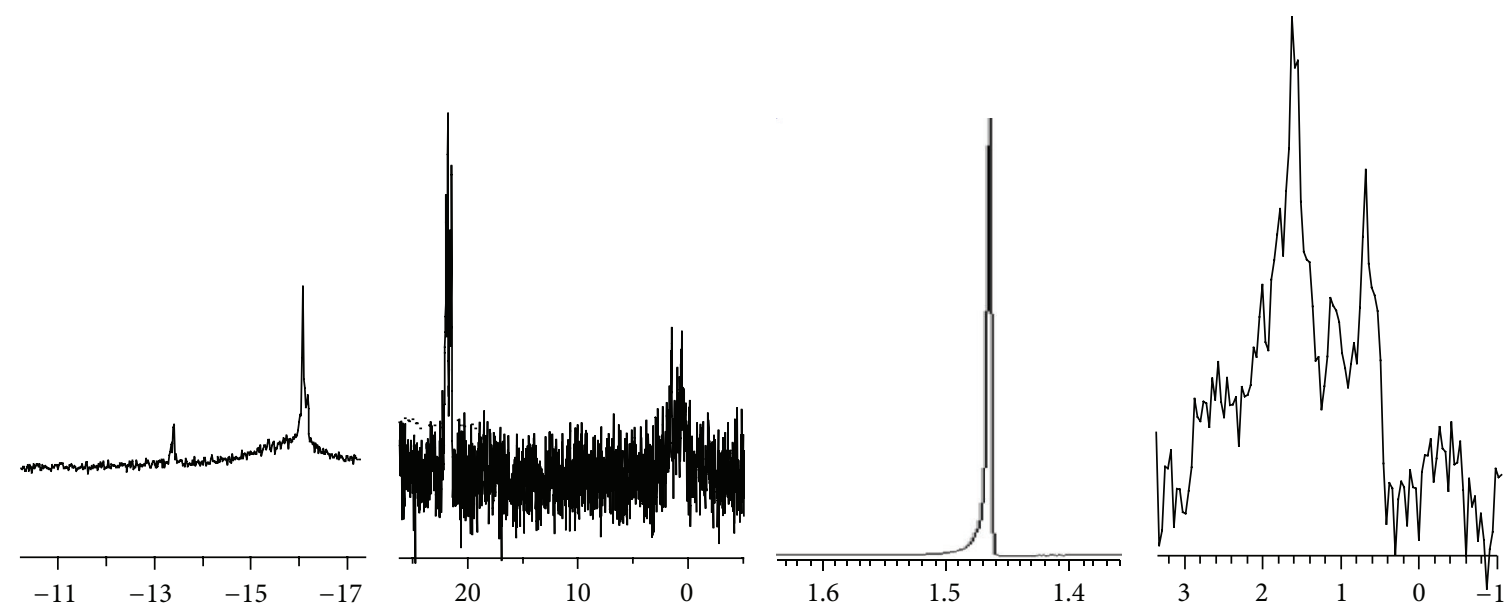

(a)

(b)

(c)

(d)

Figure 3: ${ }^{31}$ P NMR spectra of (a) PZ, (b) PZ-HEMA-1:3, (c) PZ-HEMA-1: 6, and (d) PZ-HEMA-LA.

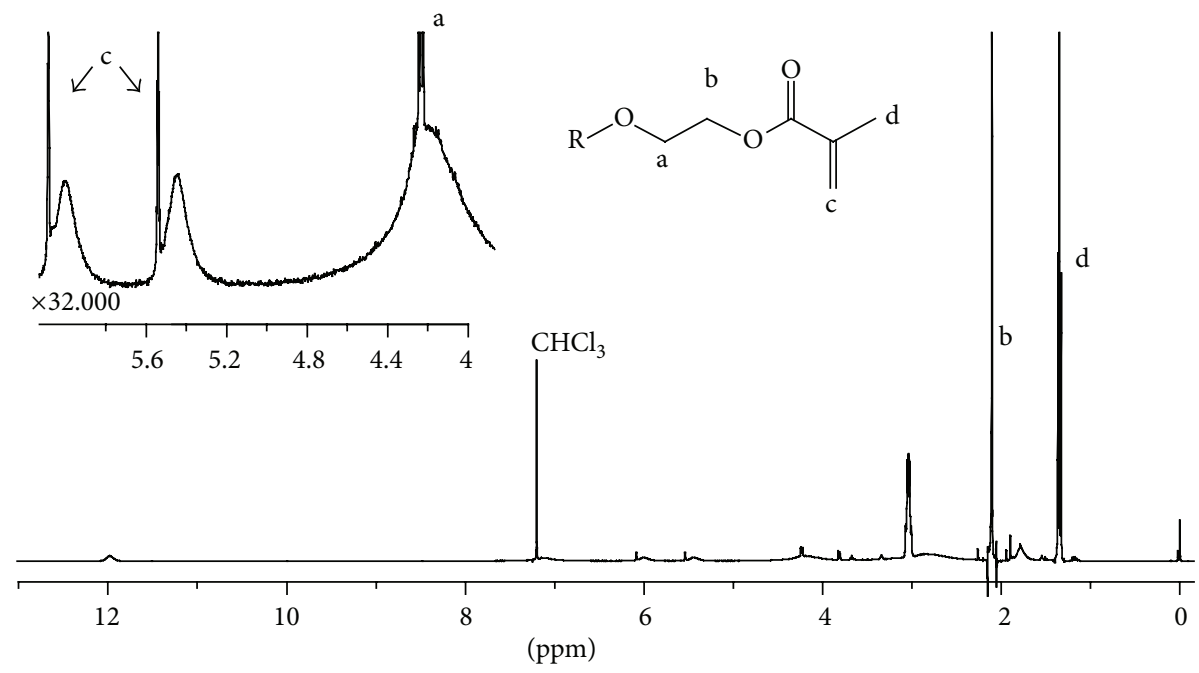

(a)

A

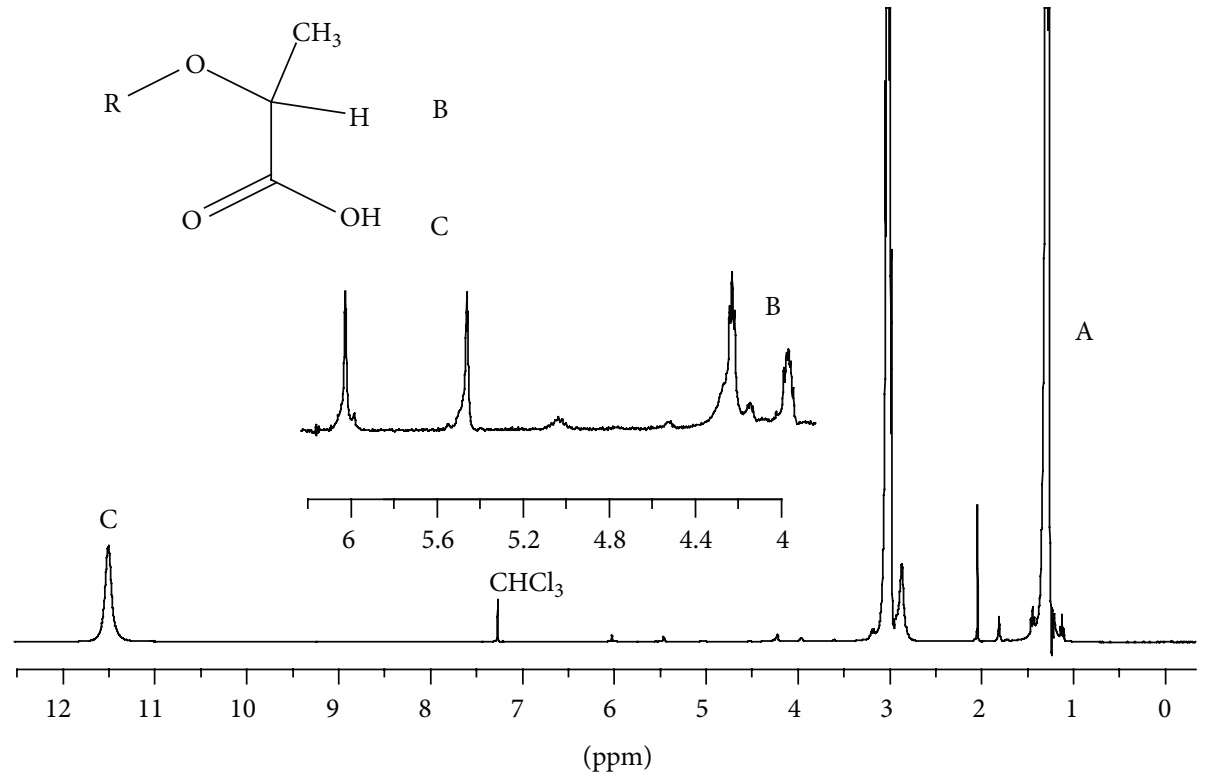

(b)

Figure 4: ${ }^{1} \mathrm{H}$ NMR spectra of (a) PZ-HEMA-1: 6 and (b) PZ-HEMA-LA. 


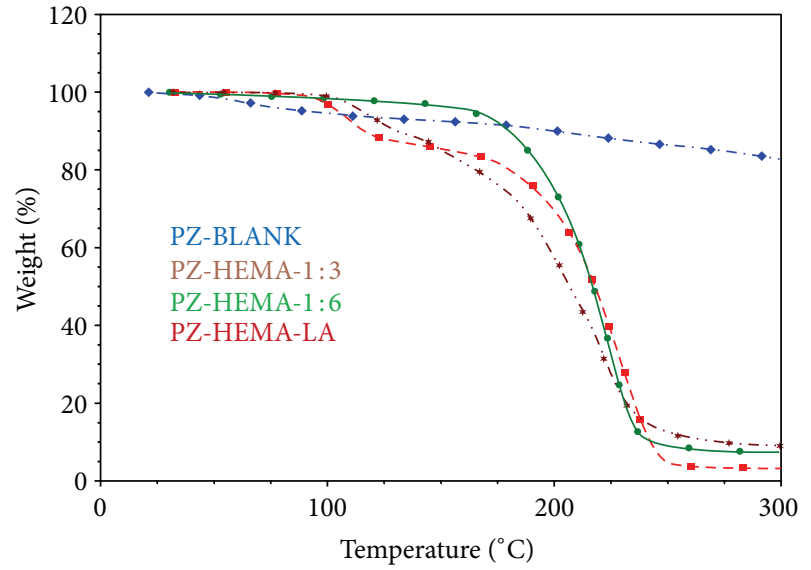

Figure 5: TGA thermograms of PZ BLANK, PZ-HEMA-1:3, PZHEMA-1: 6 , and PZ-HEMA-LA.

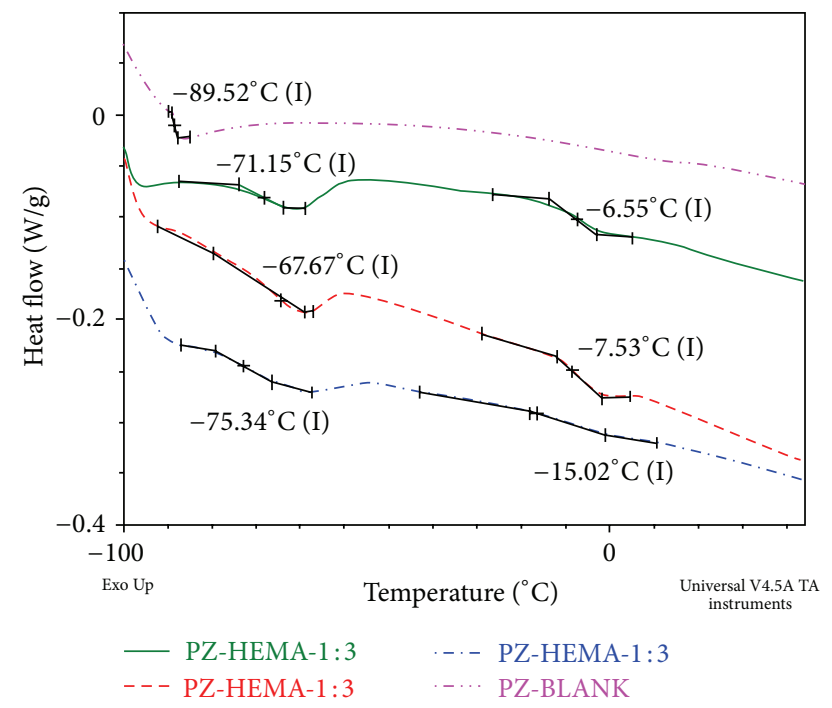

Figure 6: DSC Thermograms of PZ, PZ-HEMA-1:3, PZ-HEMA$1: 6$, and PZ-HEMA-LA.

the majority of the end double bonds are on the material. In addition, the peaks to $\mathrm{OH}$ in $4.9 \mathrm{ppm}$ (HEMA) and $3.4 \mathrm{ppm}$ $(\mathrm{AL})$ are not present in the spectrum.

The thermal stability of the polymers was analyzed by TGA (Figure 5). PZ lost about $5 \%$ of weight between $50^{\circ} \mathrm{C}$ and $100^{\circ} \mathrm{C}$ due to residual monomer evaporation. Between $200^{\circ} \mathrm{C}$ and $300^{\circ} \mathrm{C}$ there is another $5 \%$ loss of weight, which is attributed to the elimination of chlorine. Nevertheless, the $\mathrm{PZ}$ is fairly stable up to $300^{\circ} \mathrm{C}$.

In contrast, when the inorganic back bone is substituted for organic molecules the temperature of decomposition decreased at $\sim 225^{\circ} \mathrm{C}$; according to the literature, the pure poly(HEMA) began its decomposition at $\sim 300^{\circ} \mathrm{C}$. This means that HEMA was grafted in the inorganic chain and changed the thermal stability of PZ.
PZ-HEMA and PZ-HEMA-LA are quite stable up to $100^{\circ} \mathrm{C}$, the stability of PZ-HEMA increases with the content of HEMA attached on PZ because of the good thermal stability of HEMA, the initial thermal decomposition of poly(HEMA) exhibited at $195^{\circ} \mathrm{C}$ [16]. In PZ-HEMA-LA the decomposition temperature of LA starts at $109^{\circ} \mathrm{C}$, this value is much less than of the initial decomposition of the PLA at $\sim 300^{\circ} \mathrm{C}$ [17]. Excluding monomer evaporation in $\mathrm{PZ}$, its thermal stability is greater than that observed in the copolymers.

The thermal transitions of the polymers were determined by DSC (Figure 6). The obtained data indicate that all polymers are flexible above $0^{\circ} \mathrm{C}$. PZ showed a single $T_{g}$ at $-90^{\circ} \mathrm{C}$ while both PZ-HEMA and PZ-HEMA-LA have two $T_{g}$ 's: (a) for PZ-HEMA-1: $3-71^{\circ} \mathrm{C}$ and $-6.6^{\circ} \mathrm{C}$; (b) for PZ-HEMA-1: 6 $-67^{\circ} \mathrm{C}$ and $-7.5^{\circ} \mathrm{C}$; and (c) for PZ-HEMA-LA $-75^{\circ} \mathrm{C}$ and $-15^{\circ} \mathrm{C}$. The lowest $T_{g}$ value shown by each copolymer corresponds to the PZ backbone. The $T_{g}$ of PZ-HEMA-LA at $-15^{\circ} \mathrm{C}$ corresponds to the LA grafted on the PZ backbone. The $T_{g}$ of PZ-HEMA at about $-7^{\circ} \mathrm{C}$ is attributed to the HEMA chemically attached to the PZ backbone. The observed $T_{q}$ temperatures are similar to those reported elsewhere $[14,18]$.

The properties of the poly(organophosphazenes) depend on the type of side groups linked to the polymer chain. If the side groups are small or are highly flexible organic units, like 2-butenoxy or trifluoroethoxy, the polymers will show low glass transition temperatures $\left(-100\right.$ to $\left.-30^{\circ} \mathrm{C}\right)$ [16].

The surface of the polymers was examined by SEM (Figure 7). The PZ was an amorphous white solid and shows a semiuniform surface while the copolymers show distinctive characteristics. PZ-HEMA-1:3 and PZ-HEMA$1: 6$ show a rod like microstructure that is enhanced as the concentration of HEMA; it is possible that polyphosphazene had a crosslinking reaction between itself and conducive to a geometry structure. PZ-HEMA-PLA shows a rod structure with more plastic appearance. Thus, morphology depends on the type of the substituent attached to the PZ backbone [19].

After obtaining the copolymers, it is intended to add them to an acrylic resin to increase the mechanical properties and subsequently will be made of composite fibers by electrospinning technique to improve their lifetime.

\section{Conclusions}

Poly(dichlorophosphazene) was prepared directly by melt ring-opening polymerization of hexachlorocyclotriphosphazene. This polymer was useful for the design and synthesis of Poly [(2-hydroxyethyl-methacrylate)-graft-poly(lactic-acid)phosphazene] and poly[bis(2-hydroxyethyl-methacrylate)phosphazene] by ring-opening polymerization reactions, at different concentrations of the substituents. The incorporation of organic substituents HEMA and AL was proved by FTIR, NMR, and DSC. All polymers are flexible above $0^{\circ} \mathrm{C}$ and are thermally stable up to $100^{\circ} \mathrm{C}$. The morphology of the polymers was considerably modified by the incorporation of substituents and will be of great importance when testing copolymers in dental resins. The PZ-HEMA-1: 6 copolymer yields the best results and suggest that it could potentially be used in biomedical applications such as dental resins. 


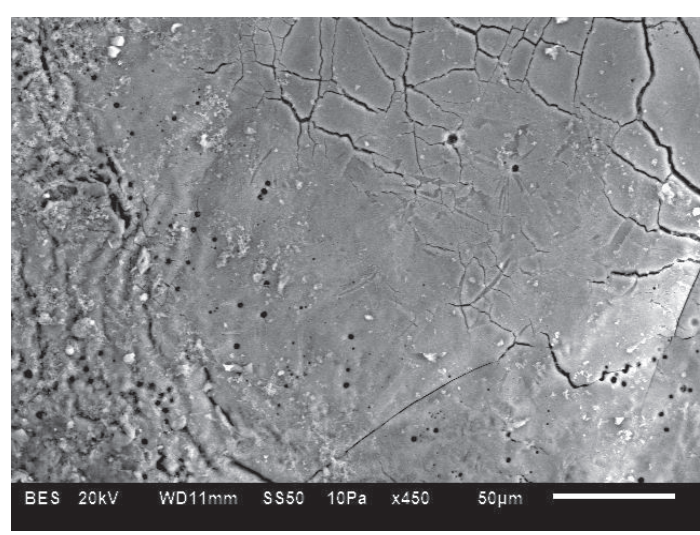

(a)

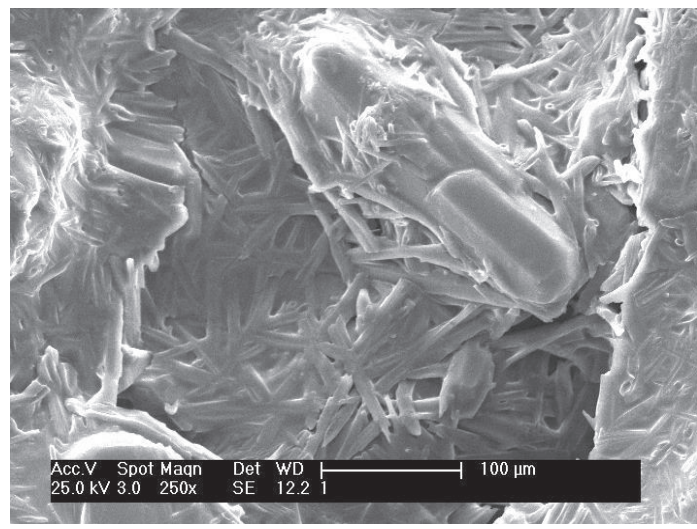

(c)

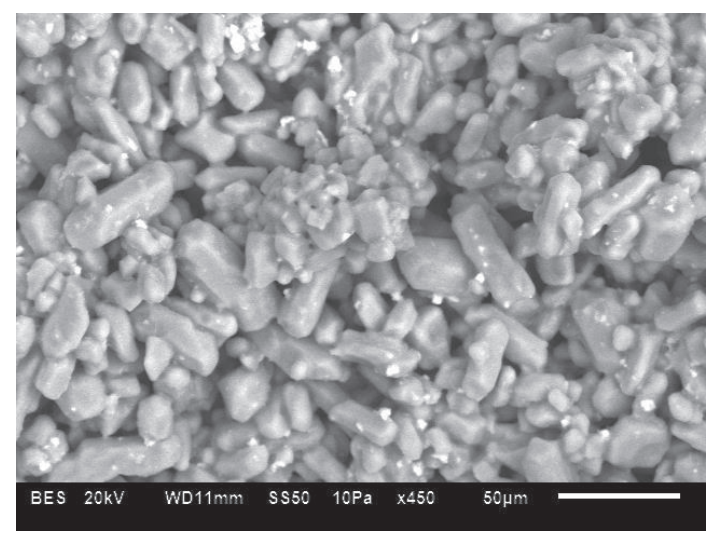

(b)

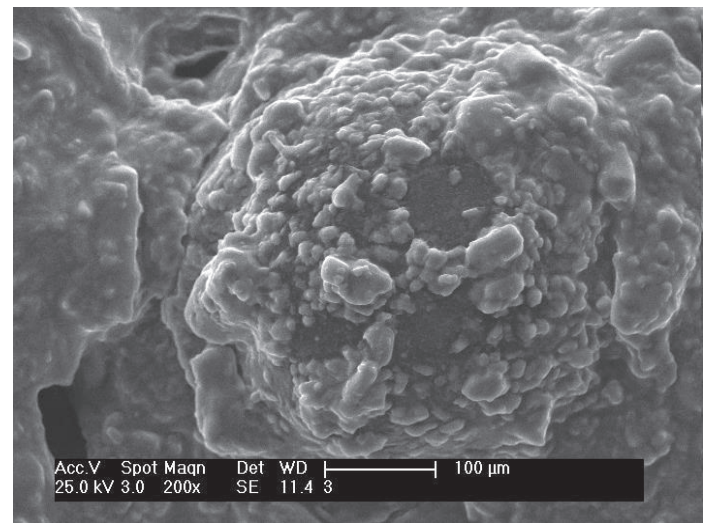

(d)

FIgure 7: SEM images of (a) PZ, (b) PZ-HEMA-1:3, (c) PZ-HEMA-1: 6, and (d) PZ-HEMA-LA.

\section{Conflict of Interests}

The authors do not have a direct financial relation or conflict of interests with the commercial identities mentioned in this submitted paper, and the commercial trademarks such as Bruker Avance, Thermo Scientific, TA Instruments, and JEOL, only were reported to guarantee the reproducibility, in the same conditions, of the different tests.

\section{Acknowledgments}

The authors acknowledge the technical support of Esteban Fregoso (TGA-DSC), Enrique Vigueras-Santiago (FTIR), and Gerardo Cedillo (RMN). The authors also acknowledge the grants of UNAM, PAPIIT-IN116809/21, and Instituto de Ciencia y Tecnología del Distrito Federal, México. They also appreciate the scholarships granted by CONACYT.

\section{References}

[1] J. Jagur-Grodzinski, "Biomedical application of functional polymers," Reactive and Functional Polymers, vol. 39, no. 2, pp. 99$138,1999$.

[2] N. R. Krogman, A. L. Weikel, N. Q. Nguyen et al., "Hydrogen bonding in blends of polyesters with dipeptide-containing polyphosphazenes," Journal of Applied Polymer Science, vol. 115, no. 1, pp. 431-437, 2010.
[3] H. R. Allcock, "Recent developments in polyphosphazene materials science," Current Opinion in Solid State and Materials Science, vol. 10, no. 5-6, pp. 231-240, 2006.

[4] A. Singh, N. R. Krogman, S. Sethuraman et al., "Effect of side group chemistry on the properties of biodegradable l-alanine cosubstituted polyphosphazenes," Biomacromolecules, vol. 7, no. 3, pp. 914-918, 2006.

[5] H. R. Allcock and S. R. Pucher, "Polyphosphazenes with glucosyl and methylamino, trifluoroethoxy, phenoxy, or (methoxyethoxy)ethoxy side groups," Macromolecules, vol. 24, no. 1, pp. 23-34, 1991.

[6] H. R. Allcock and K. B. Visscher, "Preparation and characterization of poly(organophosphazene) blends," Chemistry of Materials, vol. 4, no. 6, pp. 1182-1187, 1992.

[7] M. Gleria and R. De Jaeger, "Aspects of Phosphazene Research," Journal of Inorganic and Organometallic Polymers, vol. 11, no. 1, pp. 1-45, 2001.

[8] A. K. Andrianov, Y. Y. Svirkin, and M. P. LeGolvan, "Synthesis and biologically relevant properties of polyphosphazene polyacids," Biomacromolecules, vol. 5, no. 5, pp. 1999-2006, 2004.

[9] D. Puppi, F. Chiellini, A. M. Piras, and E. Chiellini, "Polymeric materials for bone and cartilage repair," Progress in Polymer Science, vol. 35, no. 4, pp. 403-440, 2010.

[10] Y. Cui, X. Zhao, X. Tang, and Y. Luo, "Novel micro-crosslinked poly(organophosphazenes) with improved mechanical properties and controllable degradation rate as potential biodegradable matrix," Biomaterials, vol. 25, no. 3, pp. 451-457, 2004. 
[11] P. Sharrock and G. Grégoire, "HEMA reactivity with demineralized dentin," Journal of Dentistry, vol. 38, no. 4, pp. 331-335, 2010.

[12] B. Gupta, N. Revagade, and J. Hilborn, "Poly(lactic acid) fiber: an overview, Progress in Polymer Science, vol. 32, no. 4, pp. 455482, 2007.

[13] E. Martínez-Ceballos, Síntesis y caracterización de biopolímeros modificados para usos biomédicos [M.S. thesis], Universidad Autónoma del Estado de México, 2011.

[14] R. Vera-Grazianoa, J. Palacios-Aiquisiraa, A. Martínez-Richab, F. Barcelóc, T. Halachevd, and V. M. Castañod, "On the structure and physicochemical properties of acrylic compounds," International Journal of Polymeric Materials and Polymeric Biomaterials, vol. 52, no. 2, pp. 85-95, 2003.

[15] G. Kister, G. Cassanas, and M. Vert, "Effects of morphology, conformation and configuration on the IR and Raman spectra of various poly(lactic acid)s," Polymer, vol. 39, no. 2, pp. 267-273, 1998.

[16] Y. Zhou, D. Yang, X. Gao et al., “Semi-interpenetrating polymer network hydrogels based on water-soluble N-carboxylethyl chitosan and photopolymerized poly (2-hydroxyethyl methacrylate)," Carbohydrate Polymers, vol. 75, no. 2, pp. 293-298, 2009.

[17] L.T. Lima, R. Auras, and M. Rubino, "Processing technologies for poly(lactic acid)," Progress in Polymer Science, vol. 33, no. 8, pp. 820-852, 2008.

[18] H. R. Allcock, K. B. Visscher, and Y.-B. Kim, "New polyphosphazenes with unsaturated side groups: Use as reaction intermediates, cross-linkable polymers, and components of interpenetrating polymer networks," Macromolecules, vol. 29, no. 8, pp. 2721-2728, 1996.

[19] N. R. Krogman, A. L. Weikel, N. Q. Nguyen, L. S. Nair, C. T. Laurencin, and H. R. Allcock, "Synthesis and characterization of new biomedical polymers: serine-and threonine-containing polyphosphazenes and poly(L-lactic acid) grafted copolymers," Macromolecules, vol. 41, no. 21, pp. 7824-7828, 2008. 

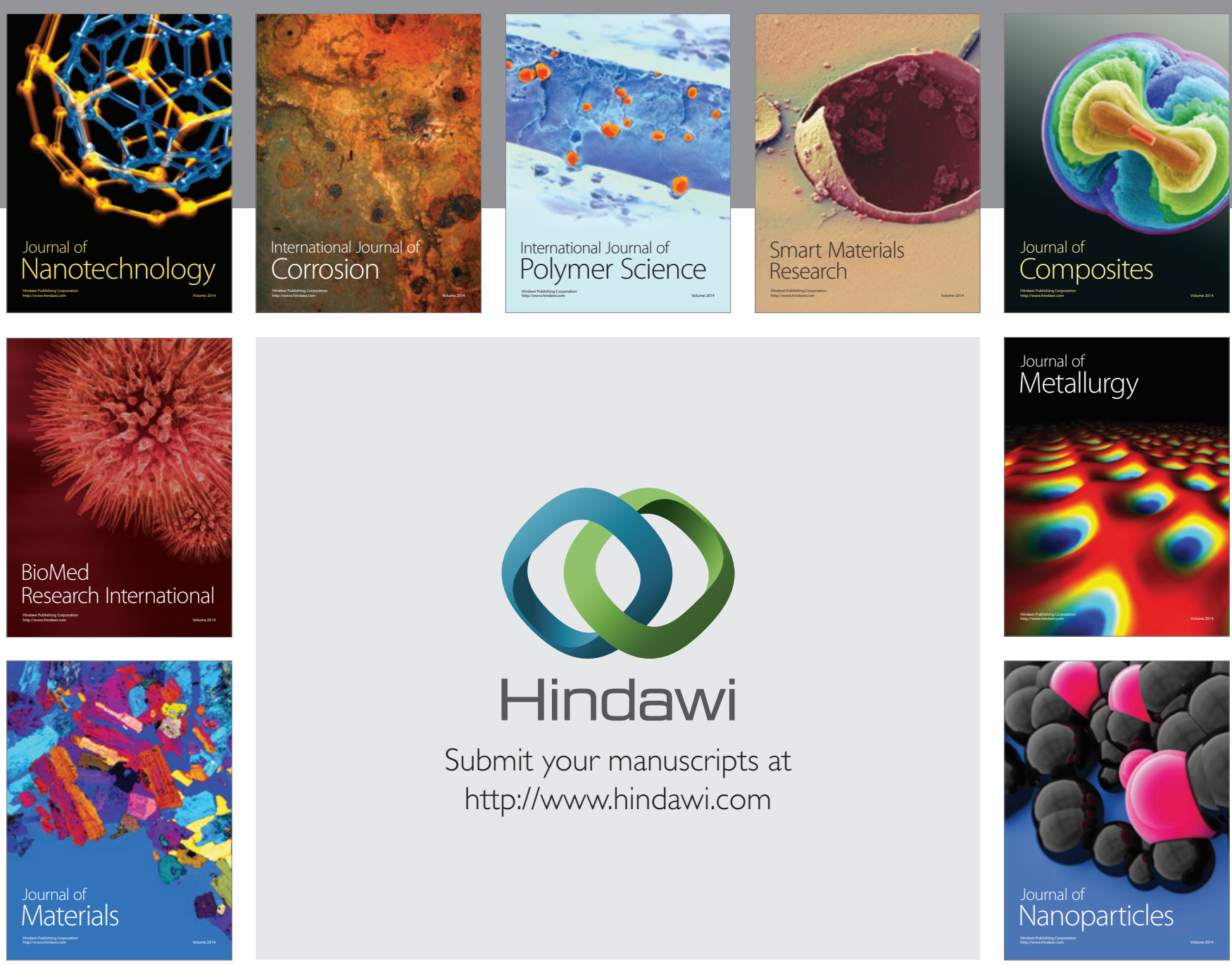

Submit your manuscripts at http://www.hindawi.com
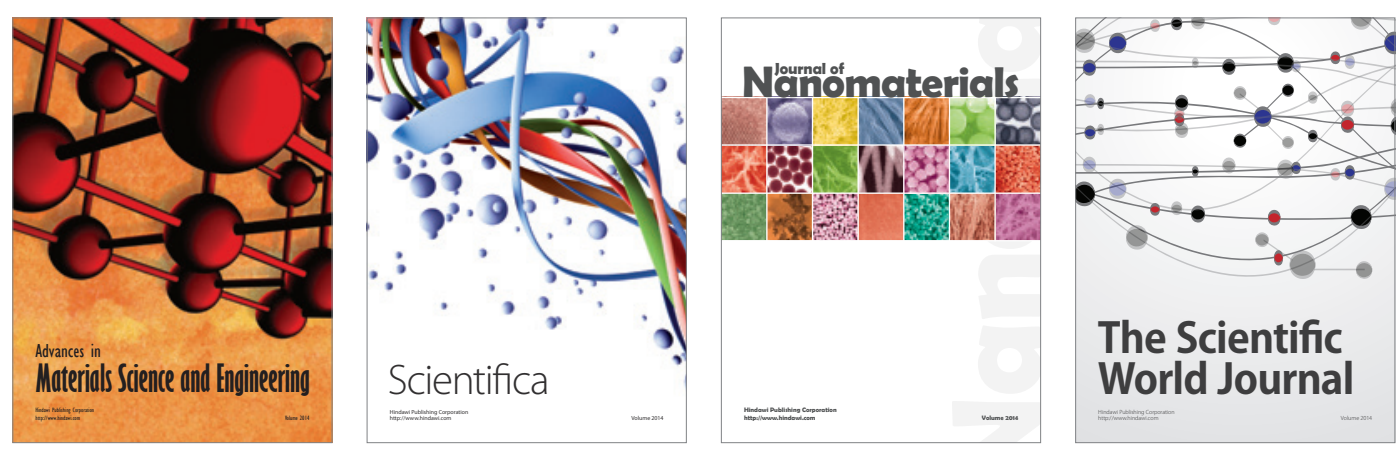

\section{The Scientific World Journal}
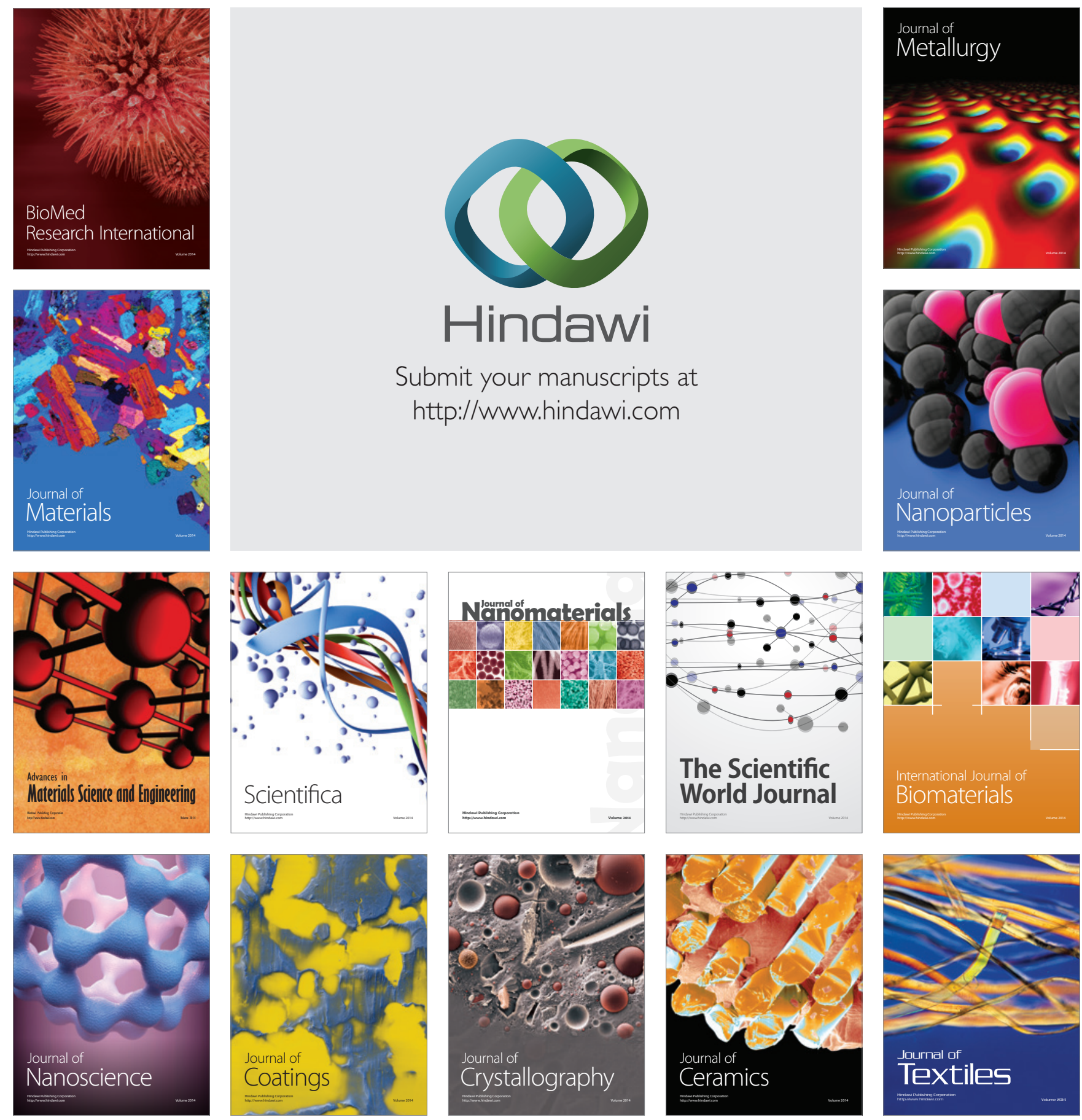